\title{
Elevated troponin level as a predictor of inpatient mortality in patients with infective endocarditis in the Southeast United States
}

\author{
William Lorson ${ }^{1,2}$, Michael P. Veve ${ }^{1,3}$, Eric Heidel ${ }^{1,2}$ and Mahmoud A. Shorman ${ }^{1,2^{*}}$ (1)
}

\begin{abstract}
Background: Despite recent improvement in management, infective endocarditis (IE) continues to be associated with considerable risk of morbidity and mortality. Early identification of predictors of inpatient mortality is key in improving patient outcomes in IE. The aim of our study was to evaluate the role of serum troponin levels measurements as a marker of increased mortality.

Methods: A case-control study included adult patients with IE admitted to a tertiary care hospital in east Tennessee between December 2012 and July 2017. Cases were defined as patients with definitive IE who died in-hospital; controls were patients who did not die in hospital. First patient admission was included only. Data collected included the patients' demographic and baseline clinical information, microbiological data, injection drug use status, elevated serum troponins levels.

Results: Two hundred eighty three patients with definitive IE were included; median (IQR) age was 41 (30-57) years, and 153 (54\%) patients were men. One-hundred sixty-four (58\%) were injection drug users. The most frequent IE type was: 167 (59\%) right-sided, 86 (30\%) left-sided, 24 (9\%) both left and right-sided, and 10 (4\%) device related. The most commonly isolated organism was Staphylococcus aureus $(n=141)$, and $64 \%$ were methicillin-resistant. Two-hundred twelve (75\%) patients had a troponin level obtained, and 57 (27\%) had an elevated troponin value. Thirty-six (13\%) patients died in-hospital; in-hospital mortality was associated elevated troponin values (adjusted odds ratio [adjOR], 7.3; 95\%Cl, 3.3-15.9), and methicillin-resistant S. aureus IE (adjOR 2.6; $95 \% \mathrm{Cl}, 1.2-5.8)$. Forty-four (16\%) patients received IE valve surgery, and none of these patients died in the hospital. Conclusion: Inpatient mortality was higher in patients with IE and elevated cardiac troponin levels compared to patients with normal levels.
\end{abstract}

Keywords: Troponin, Infective endocarditis, Mortality, Injection drug use

\section{Background}

Infective endocarditis (IE) is an infection of the endocardium and heart valves or of a prosthetic valve implant [1]. Great strides have been made in the treatment of IE since Osler's observation of the disease in the nineteenth century. However, IE continues to be a significant cause

\footnotetext{
* Correspondence: mshorman@utmck.edu

${ }^{1}$ University of Tennessee Medical Center, Knoxville, TN 37920, USA

2University of Tennessee, Graduate School of Medicine, Knoxville, TN 37920,

USA

Full list of author information is available at the end of the article
}

of morbidity and mortality [2,3]. The epidemiology of IE has changed, especially in high-income countries that have observed a significant reduction in IE related to rheumatic disease; while degenerative valvulopathies, prosthetic valve IE (PVE), IE related to cardiovascular implantable electronic devices (CIED) and IE in persons who inject drugs (PWID) have all increased [4, 5]. Presentation with different complications including heart failure, embolic events, abscess formation, conductive disorders, and large vegetation size has been associated

(c) The Author(s). 2020 Open Access This article is distributed under the terms of the Creative Commons Attribution 4.0 International License (http://creativecommons.org/licenses/by/4.0/), which permits unrestricted use, distribution, and reproduction in any medium, provided you give appropriate credit to the original author(s) and the source, provide a link to the Creative Commons license, and indicate if changes were made. The Creative Commons Public Domain Dedication waiver (http://creativecommons.org/publicdomain/zero/1.0/) applies to the data made available in this article, unless otherwise stated. 
with increased in-hospital mortality in patients with IE [6-8].

Troponins are cardiac specific proteins released in case of cardiomyocyte injury. Elevated troponin levels can be a poor predictor of patient's outcome in many disease states, including coronary artery disease, pulmonary embolism, heart failure, and other cardiac and non-cardiac conditions [9]. There have been some reports with small sample sizes on using troponin as a clinical predictor of mortality in patients with IE $[9,10]$.

The objective of this study was to describe variables that would predict an increased likelihood of inpatient mortality in patients presenting with IE, and to evaluate the role and usefulness of serum troponin levels measurements as a marker of increased mortality.

\section{Methods}

\section{Study population}

This case-control study included adult patients (aged $\geq 18$ years) with IE admitted to a tertiary care hospital in east Tennessee between December 2012 and July 2017. Data was gathered through retrospective chart review of the electronic medical record. Only the first patient admission for IE was included. The search term "endocarditis" was used on the discharge diagnoses to narrow down the search results. This yielded "endocarditis acute, sub bacterial" and "endocarditis NOS" with ICD 9 codes 421.0 and 424.9 , respectively. Patients who met inclusion criteria were confirmed to have definitive IE by the modified Duke Criteria [11].

Data collected included the patients' demographic and baseline clinical information, microbiological data according to Clinical and Laboratory Standards Institute standards, injection drug use status, hepatitis $\mathrm{C}$ status, human immunodeficiency virus (HIV) status, acute renal failure with serum creatinine level of more $2 \mathrm{mg} / \mathrm{dl}$ on presentation, requirement of hemodialysis, diabetes mellitus, atrial fibrillation, heart failure, elevated serum troponins levels within 2 days of admission, and severe sepsis/shock during admission. The study was approved by University of Tennessee Graduate School of Medicine institutional review board.

\section{Outcome measures and key definitions}

Cases were defined as patients with definitive IE who died in-hospital; controls were patients who did not die in hospital. Troponin I values were considered elevated if they were $\geq$ than $0.78 \mathrm{ng} / \mathrm{ml}$ as per manufacturers recommendation (Siemens) for critical high, first positive result for the patients were included.

\section{Statistical analyses}

This study was designed to determine risk factors for inhospital mortality for patients with IE. The exposure of interest was elevated troponin. Descriptive and bivariate analyses were utilized to describe differences in the patient population. Categorical and continuous variables were compared using the Chi-Square, Fisher's Exact, or MannWhitney U-tests. Classification and regression tree (CART) analyses were performed to identify dichotomous breakpoints in continuous variables associated with mortality. Variables associated with in-hospital mortality from bivariate analyses $(P<0.2)$ or deemed clinically relevant a priori were considered for inclusion into a multivariable logistic regression model. Variables were manually entered into the model using a backwards, step-wise approach in order to determine variables independently associated with developing in-hospital mortality while controlling for potential confounders. Other variables were excluded from the model because of unmet clinical or statistical criteria, to preserve the n:k ratio, or to prevent collinearity. The final model was evaluated for goodness-of-fit using the Hosmer-Lemeshow test. All statistics were performed with IBM SPSS Statistics for MacIntosh v.25 (IBM Corp., Armonk, NY).

\section{Results}

Two-hundred and eighty-three patients with IE were included; baseline patient characteristics are listed in Table 1. The median (IQR) age was $41(30-57)$ years, and $153(54 \%)$ patients were men. The median (IQR) length of hospital stay was 14 (9-24) days, and 24 (9\%) patients left against medical advice. One-hundred sixtyfour (58) patients injected illicit drugs, and 110 patients (39\%) were positive for hepatitis $\mathrm{C}$ virus. The most frequent IE type was: 167 (59\%) right-sided, 86 (30\%) leftsided, 24 (9\%) both left and right-sided, and 10 (4\%) device related. Two-hundred twelve (75\%) patients had a troponin level obtained, and 57 (27) had an elevated troponin value. Table 2 includes patient characteristics of patients with a troponin value on admission.

Two-hundred eighty-one organisms were isolated from 249 (88\%) patients; 34 (12\%) patients had culture negative IE. The most commonly isolated aggregate organisms were 91 (32\%) methicillin-resistant Staphylococcus aureus, 50 (18\%) methicillin-sensitive S. aureus, 38 (14\%) Enterococcus spp., 26 (9\%) Streptococcus spp., 17 (6\%) Pseudomonas aeruginosa, 5 (2\%) other Gramnegatives (Klebsiella spp., Enterobacter spp., and Serratia spp.), and 19 (7\%) other organisms.

Thirty-six (13\%) patients died in-hospital due to any cause. The results of bivariate analyses and clinical rationale dictated the variables selected for inclusion into a multivariable regression model (Table 3). Variables associated with in-hospital mortality were elevated troponin (adjusted odds ratio [adjOR], 7.3; 95\%CI, 3.3-15.9), and MRSA IE (adjOR 2.6; 95\%CI, 1.2-5.8). Variables identified to significantly covary with elevated troponin values were: acute renal dysfunction, left-sided endocarditis, severe sepsis/ shock, and septic emboli. Hepatitis $\mathrm{C}$ virus was excluded as 
Table 1 Baseline characteristics of infective endocarditis patients who survived and died

\begin{tabular}{|c|c|c|c|c|}
\hline Characteristic $n(\%)$ or median (IQR) & Total Population $n=283$ & Died in Hospital $n=36$ & Alive $n=247$ & $P$-value \\
\hline \multicolumn{5}{|l|}{ Patient Characteristics } \\
\hline Age, years & $41(30-57)$ & $46(33-63)$ & $40(29-56)$ & 0.14 \\
\hline Sex, male & $153(54 \%)$ & $24(67 \%)$ & $129(52 \%)$ & 0.10 \\
\hline \multicolumn{5}{|l|}{ Comorbidities } \\
\hline HIV/AIDS & $4(1 \%)$ & 0 & $4(62 \%)$ & 1.0 \\
\hline Injection drug use & $164(58 \%)$ & $24(67 \%)$ & $140(57 \%)$ & 0.26 \\
\hline Hepatitis C virus & 110 (39\%) & $7(19 \%)$ & $103(42 \%)$ & 0.01 \\
\hline Diabetes mellitus & $40(14 \%)$ & $5(14 \%)$ & $35(14 \%)$ & 0.96 \\
\hline Heart failure & $64(23 \%)$ & $8(22 \%)$ & $56(23 \%)$ & 1.0 \\
\hline Atrial fibrillation & $31(110 \%)$ & 7 (19\%) & $24(10 \%)$ & 0.09 \\
\hline Hemodialysis & $15(5 \%)$ & 0 & $15(6 \%)$ & 0.23 \\
\hline Acute renal failure/hemodialysis & $99(35 \%)$ & $27(75 \%)$ & $72(29 \%)$ & $<0.001$ \\
\hline Septic shock & $93(33 \%)$ & $28(78 \%)$ & $65(26 \%)$ & $<0.001$ \\
\hline Troponin obtained & $212(75 \%)$ & $33(92 \%)$ & $179(73 \%)$ & 0.01 \\
\hline \multicolumn{5}{|l|}{ Infection Characteristics and Outcomes } \\
\hline Septic Emboli & $151(54 \%)$ & $27(75 \%)$ & $124(50 \%)$ & 0.005 \\
\hline Left-sided IE & $86(30 \%)$ & $18(50 \%)$ & $68(28 \%)$ & 0.01 \\
\hline IE Valve Surgery & $44(16 \%)$ & 0 & $44(18 \%)$ & 0.01 \\
\hline MRSA IE & $91(32 \%)$ & $16(44 \%)$ & $75(30 \%)$ & 0.09 \\
\hline LAMA & $24(9 \%)$ & 0 & $24(10 \%)$ & 0.05 \\
\hline
\end{tabular}

a variable of interest due to the lack of causal inference related to this association. Significant collinearity $(P<0.001)$ was identified between elevated troponin levels and atrial fibrillation, severe sepsis/shock, acute renal failure, leftsided IE, and septic emboli, which ultimately precluded inclusion of these variables into the final parsimonious model. Given that no patients who received IE valve surgery died, this variable was unable to converge in the final model and was excluded.

Table 2 Characteristics of infective endocarditis patients with troponin levels

\begin{tabular}{|c|c|c|c|}
\hline Characteristic $n(\%)$ or median (IQR) & Elevated Troponin Level $n=57$ & Normal Troponin level $n=155$ & $P$-value \\
\hline \multicolumn{4}{|l|}{ Patient Characteristics } \\
\hline Age, years & $44(30-59)$ & $40(30-55)$ & 0.5 \\
\hline Sex, male & $27(47 \%)$ & $74(48 \%)$ & 1.0 \\
\hline \multicolumn{4}{|l|}{ Comorbidities } \\
\hline Injection Drug Use & $34(60 \%)$ & $90(58 \%)$ & 0.84 \\
\hline Hepatitis $C$ virus & $14(25 \%)$ & $74(48 \%)$ & $<0.001$ \\
\hline Diabetes mellitus & $7(12 \%)$ & $22(14 \%)$ & 0.72 \\
\hline Heart failure & $17(30 \%)$ & $17(30 \%)$ & 0.34 \\
\hline Atrial fibrillation & $5(9 \%)$ & $21(14 \%)$ & 0.35 \\
\hline Acute Renal failure/Hemodialysis & $30(53 \%)$ & $50(32 \%)$ & 0.007 \\
\hline Sepsis/septic shock & $40(70 \%)$ & $43(28 \%)$ & $<0.001$ \\
\hline \multicolumn{4}{|l|}{ Infection Characteristics and Outcomes } \\
\hline Septic emboli & $49(86 \%)$ & $69(45 \%)$ & $<0.001$ \\
\hline Left-sided IE & $31(54 \%)$ & $37(24 \%)$ & $<0.001$ \\
\hline Valve surgery & $16(28 \%)$ & $17(11 \%)$ & 0.002 \\
\hline Died in-hospital & 19 (33\%) & $14(9 \%)$ & $<0.001$ \\
\hline
\end{tabular}


Table 3 Variables associated with all-cause, in-hospital mortality ${ }^{a}$

\begin{tabular}{|c|c|c|c|c|}
\hline Characteristic & Unadjusted OR 95\%Cl & $P$-value & Adjusted OR 95\%Cl & $P$-value \\
\hline Elevated troponin & $6.1(2.9-12.9)$ & $<0.001$ & $7.3(3.3-15.9)$ & $<0.001$ \\
\hline Severe Sepsis/Shock & $9.8(4.3-22.3)$ & $<0.001$ & Not Tested & - \\
\hline Acute renal failure & $7.2(3.3-16.3)$ & $<0.001$ & Not Tested & - \\
\hline Septic emboli & $3.0(1.3-6.6)$ & 0.005 & Not Tested & - \\
\hline Left-sided IE & $2.6(1.3-5.4)$ & 0.006 & Not Tested & - \\
\hline Atrial Fibrillation & $2.2(0.89-5.7)$ & 0.09 & $2.7(0.97-7.8)$ & 0.06 \\
\hline Age greater than 40 years & $1.9(0.95-4.1)$ & 0.07 & $2.0(0.9-4.6)$ & 0.09 \\
\hline MRSA IE & $1.8(0.9-3.7)$ & 0.12 & $2.6(1.2-5.8)$ & 0.02 \\
\hline Heart failure & $0.97(0.42-2.3)$ & 0.95 & Not Tested & - \\
\hline Valve surgery & $0.85(0.81-0.9)$ & 0.01 & Not Tested & - \\
\hline
\end{tabular}

${ }^{a}$ Hosmer-Lemeshow Goodness-of-fit test: Chi-square, 1.6; $P$-value, 0.90

Given the co-linearity observed between renal dysfunction elevated troponin values, a sub-group analysis of patients without acute renal failure was performed. The results of the bivariate and multivariable models were similar in nature to the original analysis, as troponin values remained significantly associated with in-hospital mortality (adjOR 3.3; 95\%CI, 1.2-9.0).

\section{Discussion}

Our study found that patients with elevated troponin values and MRSA IE were associated with increased in hospital mortality. The overall observed inpatient mortality rate was $12 \%$, which is lower than published literature [3]; one explanation is the large number of patients with mainly associated right-sided IE (65\%).

In our study, which is to our knowledge the largest todate evaluating the role of troponin as a predictor of mortality, patients presenting with an elevated troponin had an adjusted OR of 2.5 of death before discharge (95\% CI 1.1-5.6), confirming previous published reports describing an inverse relationship between survival and increased troponin levels, and indicating the importance of obtaining troponin levels for admitted patients with IE to help stratify their mortality risk $[9,10]$.

Few previous reports with small sample sizes described elevated troponin as surrogate for increased likelihood of death in patients with IE. Purcell et al. reported increased troponin levels in $65 \%$ of 51 patients with IE studied, the study also described an association with central nervous system involvement and death [12]. Tsenovoy et al. reported increased troponin I levels in $57 \%$ of 62 patients with IE, with in-hospital mortality or valve replacement occurring in 18 patients (51\%) of the increased troponin arm; these findings were also demonstrated by Stancoven and colleagues $[13,14]$. Gucuk et al. found that troponin levels could also predict one-year survival rates in IE, with $41 \%$ mortality rate during follow up in patients with higher troponin levels during initial hospitalization [9].
There has been postulation that an elevated troponin level indicates myocardial involvement of infection. This would likely indicate a more significant infection compared to only endocardium or valvular involvement. Another possibility is that elevated troponins are associated with more severe sepsis, such as that associated with demand ischemia $[9,12]$.

Other predictors of inpatient mortality described in our report included patients older than 40 years of age, severe sepsis or shock on presentation; these predictors are similar to previously described literature emphasizing the importance of initial presentation with multiorgan dysfunction and risk of systemic embolization [15-20]. In a study by Ferrera et al., IE patients presenting with atrial fibrillation had higher in-hospital mortality independently from other relevant clinical variables [21]. Our findings are similar, but ultimately atrial fibrillation was not associated with in-hospital mortality in the final parsimonious model.

We did find an association between different organisms including MRSA and mortality, some reports suggested increased mortality with $S$. aureus [22, 23], and other reports did not [24]. The PWID population remains of highinterest due to increasing incidence of IE and significant morbidity and long-term complication [5].

The limitations of our study included that it is a single center study with high percentage of PWID, and the results may not be reflective of the general population. However, given the lasting negative effects of the opioid epidemic in the United States, we feel these data likely represent a common patient population particularly throughout the southern United States $[25,26]$. Another limitation was in the retrospective data collection through the electronic medical record, limiting the ability to gather additional information on each patient especially pertaining to drug use and/or other variables that may be associated with in-patient mortality. However, we attempted to correct for confounding variables through multivariable logistic regression methods. 
We did not collect information on treatment regimens and need for surgery during hospitalization, and patients leaving against medical advice and loss to follow up data.

\section{Conclusion}

The incidence of inpatient mortality was higher in patients with IE and elevated cardiac troponin I levels compared to patients with normal levels; cardiac troponin I may have potential as a prognostic marker in IE.

\section{Abbreviations}

HIV/AIDS: Human immunodeficiency virus/acquired immune deficiency; IE: Infective endocarditis; LAMA: Left against medical advice; MRSA: Methicillin-resistant Staphylococcus aureus; PWID: People who inject drugs

\section{Acknowledgements}

None.

\section{Declarations}

None.

\section{Authors' contributions}

MS designed the research and wrote the manuscript. WL collected the data and established the database, helped writing the manuscript. MV analyzed the data statistically and helped writing manuscript. EH analyzed the data statistically. All authors read and approved the final manuscript.

\section{Funding}

No funding was required for this study.

\section{Availability of data and materials}

The datasets analyzed during the current study are not publicly available due to protection of the patients' privacy, but are available from the corresponding author on reasonable request.

\section{Ethics approval and consent to participate}

The study was reviewed and approved by the ethic committee of the graduate school of medicine, University of Tennessee, approval number 4304, patient consent was waived as this was a retrospective chart review.

\section{Consent for publication}

Not applicable.

\section{Competing interests}

The authors declare that they have no competing interests.

\section{Author details}

${ }^{1}$ University of Tennessee Medical Center, Knoxville, TN 37920, USA.

${ }^{2}$ University of Tennessee, Graduate School of Medicine, Knoxville, TN 37920, USA. ${ }^{3}$ University of Tennessee Health Science Center, Knoxville, TN 37920, USA.

Received: 30 September 2019 Accepted: 30 December 2019 Published online: 08 January 2020

\section{References}

1. Thuny F, Grisoli D, Cautela J, Riberi A, Raoult D, Habib G. Infective endocarditis: prevention, diagnosis, and management. Can J Cardiol. 2014; 30(9):1046-57. https://doi.org/10.1016/j.cjca.2014.03.042.

2. Grinberg M, Solimene MC. Historical aspects of infective endocarditis. Revista da Associacao Medica Brasileira (1992). 2011;57(2):228-33 Published Online First:04/05/ 2011

3. Thuny F, Giorgi R, Habachi R, et al. Excess mortality and morbidity in patients surviving infective endocarditis. Am Heart J. 2012;164(1):94-101. https://doi.org/10.1016/j.ahj.2012.04.003.

4. Ambrosioni J, Hernandez-Meneses M, Téllez A, Hospital Clinic Infective Endocarditis Investigators, et al. The changing epidemiology of infective endocarditis in the twenty-first century. Curr Infect Dis Rep. 2017;19(5):21. https://doi.org/10.1007/s11908-017-0574-9.

5. Wurcel AG, Anderson JE, Chui KKH, Skinner S, Knox TA, Snydman DR, et al Increasing infectious endocarditis admissions among young people who inject drugs. Open Forum Infect Dis. 2016;3(3):ofw157Published online 2016 Jul 26. https://doi.org/10.1093/ofid/ofw157.

6. Sy RW, Chawantanpipat C, Richmond DR, Kritharides L. Development and validation of a time-dependent risk model for predicting mortality in infective endocarditis. Eur Heart J. 2011;32:2016-26.

7. Hasbun R, Vikram HR, Barakat LA, Buenconsejo J, Quagliarello VJ. Complicated left-sided native valve endocarditis in adults: risk classification for mortality. JAMA. 2003;289:1933-40.

8. Costa MA, Wollmann DR, Campos AC, et al. Risk index for death by infective endocarditis: a multivariate logistic model. Rev Bras Cir Cardiovasc. 2007; 22(2):192-200

9. Gucuk Ipek E, Guray Y, Acar B, et al. The usefulness of serum troponin levels to predict 1-year survival rates in infective endocarditis. Int J Infect Dis. 2015; 34:71-5. https://doi.org/10.1016/j.jijid.2015.03.004 published Online First: 07/ 03/2015.

10. Thoker ZA, Khan KA, Rashid I, et al. Correlation of cardiac troponin I levels with infective endocarditis \& its adverse clinical outcomes. Int J Cardiol. 2016;222:661-4. https://doi.org/10.1016/j.ijcard.2016.07.130.

11. Li JS, Sexton DJ, Mick N, Nettles R, Fowler VG Jr, Ryan T, et al. Proposed modifications to the Duke criteria for the diagnosis of infective endocarditis. Clin Infect Dis. 2000;30(4):633-8. https://doi.org/10.1086/313753 PubMed PMID: 10770721

12. Purcell JB, Patel $M$, Khera $A$, et al. Relation of troponin elevation to outcome in patients with infective endocarditis. Am J Cardiol. 2008;101(10):1479-81. https://doi.org/10.1016/j.amjcard.2008.01.031 published Online First: 2008/ $03 / 17$.

13. Tsenovoy P, Aronow WS, Joseph J, et al. Patients with infective endocarditis and increased cardiac troponin I levels have a higher incidence of inhospital mortality and valve replacement than those with normal cardiac troponin I levels. Cardiology. 2009;112(3):202-4. https://doi.org/10.1159/ 000149573 published Online First: 2008/08/01.

14. Stancoven $A B$, Shiue $A B$, Khera $A$, et al. Association of troponin $T$, detected with highly sensitive assay, and outcomes in infective endocarditis. Am J Cardiol. 2011;108(3):416-20. https://doi.org/10.1016/j.amjcard.2011.03.061.

15. Korff S, Katus HA, Giannitsis E. Differential diagnosis of elevated troponins. Heart. 2006:92(7):987-93. https://doi.org/10.1136/hrt.2005.071282.

16. Mehta RL, Pascual MT, Soroko S, et al. Spectrum of acute renal failure in the intensive care unit: the PICARD experience. Kidney Int. 2004;66(4):1613-21. https://doi.org/10.1111/j.1523-1755.2004.00927.x.

17. Wallace SM, Walton BI, Kharbanda RK, et al. Mortality from infective endocarditis: clinical predictors of outcome. Heart. 2002;88(1):53-60.

18. Chu VH, Cabell CH, Benjamin DK, et al. Early predictors of in-hospital death in infective endocarditis. Circulation. 2004;109(14):1745-9. https://doi.org/10. 1161/01.CIR.0000124719.61827.7F published Online First: 2004/03/22.

19. Rodger L, Glockler-Lauf SD, Shojaei E, et al. Clinical characteristics and factors associated with mortality in first-episode infective endocarditis among persons who inject drugs. JAMA. 2018;1:e185220.

20. Thuny F, Avierinos JF, Tribouilloy C, et al. Impact of cerebrovascular complications on mortality and neurologic outcome during infective endocarditis: a prospective multi Centre study. Eur Heart J. 2007;28(9):115561. https://doi.org/10.1093/eurheartj/ehm005.

21. Ferrera C, Vilacosta I, Fernández C, López J, Sarriá C, Olmos C, et al. Usefulness of new-onset atrial fibrillation, as a strong predictor of heart failure and death in patients with native left-sided infective endocarditis. Am J Cardiol. 2016;117(3):427-33. https://doi.org/10.1016/j.amjcard.2015.11. 012 Epub 2015 Nov 18.

22. Moss R, Munt B. Injection drug use and right sided endocarditis. Heart. 2003:89(5):577-81. https://doi.org/10.1136/ heart.89.5.577.

23. Klein M, Wang A. Infective endocarditis. J Intensive Care Med. 2016:31(3): 151-63. https://doi.org/10.1177/ 0885066614554906.

24. De Rosa FG, Cicalini S, Canta F, Audagnotto S, Cecchi E, Di Perri G. Infective endocarditis in intravenous drug users from Italy: the increasing importance in HIV-infected patients. Infection. 2007;35(3):154-60. https://doi.org/10. 1007/s15010-007-5125-0.

25. Rudasill SE, Sanaiha Y, Mardock AL, et al. Clinical outcomes of infective endocarditis in injection drug users. J Am Coll Cardiol. 2019:73:559-70. 
26. Keeshin SW, Feinberg J. Endocarditis as a marker for new epidemics of injection drug use. Am J Med Sci. 2016;352:609-14.

\section{Publisher's Note}

Springer Nature remains neutral with regard to jurisdictional claims in published maps and institutional affiliations.

Ready to submit your research? Choose BMC and benefit from:

- fast, convenient online submission

- thorough peer review by experienced researchers in your field

- rapid publication on acceptance

- support for research data, including large and complex data types

- gold Open Access which fosters wider collaboration and increased citations

- maximum visibility for your research: over $100 \mathrm{M}$ website views per year

At BMC, research is always in progress. 